\title{
Bilge Olarak Yunus Emre: Bilgeliğin Felsefesi Bakış Açısından Yaşam Öyküsünün Değerlendirilmesi
}

\section{Yunus Emre as a Wise Person: The Evaluation of His Life Story in the Perspective of Philosophy of Wisdom}

\author{
Araş. Gör. Özden TURGUT (iD 1
}

\begin{abstract}
$\ddot{\mathbf{O} z}$
Yunus Emre, kültürümüze bıraktığı hazineler, şiirleri ile toplumumuzun hafızasında çok değerli bir yere sahiptir. Mütevazı yaşamında, değerli olan bilginin peşinde koşmuş, yaşamın anlamı üzerinde düşünmüştür. Şiirleri, bu düşünme eyleminin ürünleri olarak değerlendirilebilir. Şiirleri de, onun dünyaya bakışını yansıtan şekilde sade ve anlaşılırdır. Şiir, sanatın bir parçası olmanın ötesinde, felsefi sorular yöneltmek için en uygun olan sanattır. Yunus Emre'nin, felsefi düşünme iddiası ortaya koymamakla birlikte, dünyayı ve insanı anlama çabası göstermesiyle ve yaşamın anlamı, neyin değerli olduğu sorusuna odaklanmasıyla, hem bilgelik hem felsefe alanına girmiş olduğu ileri sürülebilir. Bilgeliğin, bireylerin benlik bilgisinin, benlik-bütünlüğünün, öz aşkınlığın ve yaşam hakkında derin anlayışın arttığı gelişimsel bir süreç olduğu ifade edilmektedir. Buradan yola çıkarak, Yunus Emre'nin yaşam öyküsü, bakış açısı ve eserlerini bilgelik ve bilgeliğin felsefesi kavramları ile değerlendirmenin, Yunus Emre'yi daha bütünsel anlamaya katkı sunabileceği düşünülmektedir. Bu makalede, Yunus Emre'nin yaşam öyküsü ile bakış açısının, bilgelik ve bilgeliğin felsefesi açısından diğer düşünürlerle karşılaştırılarak ele alınması amaçlanmıştır. Bu makale, alan yazın taramasına dayalı bir derleme çalışmasıdır. Sonuç olarak, Yunus Emre'nin bilgelik ve bilgeliğin felsefesi kavramları ile birlikte değerlendirilmesi, eserlerinin bu perspektifle ele alınması ve bu yöndeki çalışmaların artması ile kültürümüz içerisinde halihazırda yüzyıllardır var olan bir hazinenin bugünün insanının düşünsel ve psikolojik durumuna olumlu yansımaları olacağı düşünülmektedir.
\end{abstract}

Anahtar Kelimeler: Yunus Emre, bilgelik, bilgeliğin felsefesi

Makale Türü: Alan yazın taramasına dayalı derleme

\begin{abstract}
Yunus Emre has a precious room in the memory of the community with his treasury, poems. He seeks for the valuable knowledge in his modest life and thinks on the meaning of life. His poems can be evaluated as the outputs of this thinking action. His poems are pure and straightforward likely his perspective while looking at the world. Poetry is a part of art and beyond that, poetry is the most appropriate branch of art for asking philosophical questions. Though Yunus Emre does not claim to think philosophically, it can be said that he thinks in the area of wisdom and also philosophy because of the effort he puts for understanding the world and the human being, and also the meaning of life. It is said that wisdom is a developmental process where the self-knowledge, self-coherence, self-transcendence and deep comprehension about life increases. For this reason, it is thought that evaluating Yunus Emre's life story and perspective in light of the concepts "wisdom" and "philosophy of wisdom" may contribute to the comprehension of Yunus Emre more coherently. The aim of this article is evaluating Yunus Emre's life story and perspective in comparison to various other philosophers with the perspective of wisdom and philosophy of wisdom. This article is a study that consists of literature review. Consequently, it is predicted that evaluating Yunus Emre's life story, perspective and poems in the frames of reference "wisdom" and "philosophy of wisdom" may have positive reflections on the modern individual both intellectually and psychologically.
\end{abstract}

\footnotetext{
${ }^{1}$ Afyon Kocatepe Üniversitesi, Eğitim Fakültesi, Eğitim Bilimleri Bölümü, ozden5@ hotmail.com
}

Atıf için (to cite): Turgut, Ö. (2021). Bilge olarak Yunus Emre: Bilgeliğin felsefesi bakış açısından yaşam öyküsünün değerlendirilmesi. Afyon Kocatepe Üniversitesi Sosyal Bilimler Dergisi, 23(Yunus Emre ve Türkçe Özel Sayıs1), 25-32. 
Keywords: Yunus Emre, wisdom, philosophy of wisdom

Paper Type: Literature review

\section{Giriş}

Bilgelik üzerine yapılan çalışmalar son yıllarda artmıştır. Bu çalışmaların bakış açısına göre bilgelik, bir karakter özelliğidir ve kişinin güçlü yanı olarak nitelendirilmektedir (Seligman ve Csikszentmihalyi, 2000, s.5). Felsefe ise bilgeliğin sevgisi olarak nitelenmektedir (Arslan, 1999, s.18) ve bu nedenle bilgeliğe ulaşma çabasına işaret etmektedir. Bilgelik birçok disiplinle ilişkili ve derin bir kavram olduğu için, bilgeliği farklı disiplinlerin kavramlarını kullanarak kavramaya çalışmanın ve bireysel yaşam öyküleri eşliğinde incelemenin yararlı olabileceği düşünülmektedir.

Bilgeliğin felsefesi ya da bilgelik felsefesi kavramlarına yakından bakarsak, bilgeliğin felsefesi neyin değeri olduğunu fark etmemizde akılcı yardım sunmaktadır. Ayrıca kendi yaşamımıza ve sorunlarımıza, varoluşta neyin değerli olduğunu fark etmemize entelektüel öncelik vermektedir. Bilgeliğin felsefesine göre, akılcı sorgulamanın en temel entelektüel görevi, bize, kişisel ve sosyal hayatlarımızın hayal edilen ve eleştirilen olası eylemlerini ve bu noktadan değeri olanı fark etmemize destek olmaktır (Maxwell, 2007, s.79). Dolayısıyla bilgeliğin felsefesi, insanın değerli olana karar verirken geçtiği akılcı sorgulama sürecine işaret etmektedir.

Yunus Emre, ülkemizin en önemli kültür hazinelerinden biridir. Onun değeri, yaşamı boyunca, manevi anlamda yolda olmasından ve kendisini tanımaya çaba göstermesinden kaynaklanmaktadır. Kendisinden yola çıkarak insanı olgunlaşan bir varlık olarak resmetmiştir. "Yunus miskin çigidük, bişdük elhamdülillah" (Yunus Emre, 2014) deyişi, insanın kendini tanıma ile ilgili aldığı ve alabileceği yolu işaret etmektedir. Peki, Yunus Emre'nin "pişmek" ile nitelediği süreç, bilgelik ve felsefe kavramları ile nasıl açıklanabilir? Bilgelik kavramını anlamaya çalıştığımızda, örnek bir olgu olarak Yunus Emre'nin hayat öyküsü ve bu öyküyü meydana getiren şiirlerin, insana ve içsel süreçlerine dair görüşlerinin incelenmesinin işlevsel olacağ 1 düşünülmektedir. Bu kapsamda Yunus Emre'nin yaşam öyküsü ve bağlantılı olarak eserleri, bilgelik ve felsefenin bir araya geldiği noktada yorumlanmaya çalışılmaktadır. Bu çalışmada, Yunus Emre'ye ait mısralar, Yunus Emre Divanı'ndan (Yunus Emre, 2014) alınmış ve ayrıca Yunus Emre üzerine yapılmış araştırmalardan (örn. Tatcı, 2020) faydalanılmıştır.

\section{Yunus Emre'nin Hayatı Hakkında Bilinenler}

Yunus Emre'nin hayatına yakından bakıldığında, henüz bilmediği ve kavramak istediği özel nitelikte bir bilgiye ulaşmak için büyük istek duyduğu ve bu konuda emek harcamayı gönüllü olarak seçtiği görülmektedir. Arapça ve Farsça bildiği, medrese eğitimli olduğu; ancak mütevazı olduğu için bazı şiirlerinde okuma yazma bilmediğini ifade ettiği belirtilmektedir. Ayrıca ekonomik anlamda varlığı olmadığı ifade edilmektedir. Ulaşmak istediği "bilgi" için ilk olarak Hacı Bektaşi Veli'ye, daha sonra Taptuk Emre'nin yanına gittiği söylenmektedir. Yunus Emre'nin Taptuk Emre'nin yanında odun bulma ve hazırlama görevini üstlendiği ve bu görevini büyük titizlikle yerine getirdiği anlatılmaktadır. Basit düzeyde bilginin ötesine geçmek için, ilim sahibi olan birinin çırağı olmayı seçmesi, Yunus Emre'nin özel nitelikteki bilgiye erişmek için seçtiği bir yoldur. Bir şiirinde tekrarlı olarak yönelttiği "Manası ne demektir?" (Yunus Emre, 2014) ifadesi, bilgiye ve anlama ulaşmaya ne kadar önem verdiğini göstermektedir.

Yunus Emre'nin bazı dizeleri şunlardır: "Ne varlığa sevinirim, ne yokluğa yerinirim." "Toprakdan yaratıldun yine toprakdur yirün, toprak olan kişiler n'ider bu alameti" (Yunus Emre, 2014). Yunus Emre ilk dizede dünya hayatına dair maddi varlık ile mutlu/mutsuz olmas1 arasında bağlantı olmadığını vurgular. İkinci dizede ise insanoğlunun ölümlü oluşu ve buradan yola çıkarak belki kendi ölümlülüğü üzerine düşünür. $\mathrm{Bu}$, derin düşünmedir. Modern yaklaşıma göre, derinlemesine düşünme ve akıl yürütme, anahtar felsefi becerilerdir (Presbey, 1999, s.89). 
Dolayısıyla Yunus Emre'nin filozof olma iddiası beyan etmemiş olsa da felsefi düşündüğü ileri sürülebilir. Ayrıca bilgelik felsefesine göre, edebiyat, tiyatro, müzik, dans, resim, heykel ve sanatın diğer biçimleri, sorgulamaya temel akılcı katkılar sunabilmektedir (Maxwell, 2007, s.85). Buradan hareketle, Yunus Emre'nin şiir sanatıyla bilgelik felsefesi kapsamında eserler verdiği söylenebilir.

\section{Yöntem}

$\mathrm{Bu}$ çalışma, alan yazın taramasına dayalı bir derleme çalışmasıdır. Makale kurgusunun şekillendirilmesinde, kavram olarak bilgelik, insani bir özellik olarak bilgelik ile bilgeliğin felsefi açıdan ele alınmasında Yunus Emre'nin yaşam öyküsü ve bakış açısının değerlendirilmesi amaçlanmıştır.

\section{Bilgelik ve Felsefe}

Bilgeliğin ne olduğu üzerine süregiden bir tartışma vardır. Bir görüşe göre bilgelik, bireylerin benlik bilgisinin, benlik bütünlüğünün, öz aşkınlığın ve yaşam hakkında derin anlayışın arttı̆̆ gelişimsel bir süreçtir (Aldwin, 2009, s.3). Bu bileşenlere yakından bakalım. Benlik bilgisi, bilgeliğe dahildir. $\mathrm{Bu}$, kişinin kendine dair bilginin farkında olması anlamına gelmektedir. Benlik bütünlügü̈ bilgeliğe dahildir. $\mathrm{Bu}$, benliğin bilinçli/bilinçdışı bileşenlerinin bütünleşmesi anlamına gelmektedir. Öz-aşkınlık, bilgeliğe dahildir. Aşkın, "bilincin sınırlarını aşan" anlamına gelmektedir (Husserl, 2017). Son olarak, yaşam hakkında derin anlayış, bilgelik geliştikçe artmaktadır.

Felsefe, bilgelik sevgisi anlamına gelmektedir. Felsefe, bilginin (episteme) veya bilgeliğin kendisi ya da ona sahip olma iddiası değildir. Felsefe, bilginin ve bilgiden çok daha özel olarak bilgeliğin (hikmet) sevgisidir (Arslan, 1999, s.18). Bilgeliği sevmek ile bilge olmanın eşit olmadığ özü, doğrunun sahibi olmak değil, doğruyu aramaktır. Felsefede sorular cevaplardan daha yaşamsal önemdedir (Jaspers, 2003, s.13).

Bilgelik veya hikmet, bilgiden farklı, çok daha iddialı ve çok daha zengin bir kavramdır. Bilgelik, en basit anlatımıyla, insan hayatının anlam ve değerine ilişkin derin bilgidir. Bilgelik, kendisine sahip olana mutluluk ve kurtuluş sağlayacağ 1 , hayatına anlam ve değer katacağ varsayılan anlamlı ve değerli bilgidir (Arslan, 1999, s.18). Dolayısıyla sözü edilen bu "bilgi", modern felsefe ve bilimde akla gelen bilgi ile tam olarak ayn anlama gelmemektedir.

Bilgeliğin iki türü olduğu ileri sürülmektedir. Bunlar sophia (aşkın bilgelik) ve phronesis'tir (pratik bilgelik) (Trowbridge ve Ferrari, 2011, s.89). Günümüzde "bilgi” kavramı ile karşılaşıldığında çoğu kişinin aklına ilk gelen, pratik yaşamda işlevsel olan bilgidir. Hayata anlam ve değer katacağı varsayılan bilgelik türü ise aşkın bilgeliktir denebilir.

Bilgelik üzerindeki tartışmalardan biri, bilgeliğin mümkün olup olmayacağıdır. Örneğin Pythagoras'a göre, hiçbir insan bilgeliğe sahip olamaz, sadece bilgeliği sevebilir ya da bilgeliğe özlem duyabilir. Ona göre, filozof, bilgeliğe entelektüel olarak ilgisi olan kişidir ve bu ilgi kişinin hayatının bir parçasıdır (Presbey, 1999, s.90). Felsefe ise bilgeliğin kalbindedir (White, 2013, s.8). Yunus Emre'yi anlamak istediğimizde, ona baktığımız perspektife bağlı olarak bir bilge de görebiliriz; o kendisini filozof olarak nitelemese de onu felsefe yapan biri olarak da görebiliriz.

\section{Felsefe ile Bilgelik Perspektifinden Bilgi ve Yunus Emre Açısından Bilginin Yeri}

Felsefenin başlangıç adımlarına bakıldığında, bilgeliğe sahip olmak, doğal dünyayı yöneten kuralları bilmek anlamına gelmektedir (Trowbridge ve Ferrari, 2011, s.90). Bu bakış açısı daha sonra 17. ve 18. yüzyıllarda öne çıkan batılı filozoflar için de büyük oranda geçerlidir. Ancak bilgeliğin, doğal dünyanın bilgisinden fazlasını gerektirdiği düşüncesi mevcuttur. 
"Sophia" ve "phronesis" olarak nitelenen bilgelik türleri, felsefenin bilgiye bakışını anlamak için tanımlanmaktadır. Felsefenin öncülerine bakıldığında Aristoteles’in insanın içsel süreçlerini, duygularını önemsediğini görmekteyiz. Aristoteles'e göre iyi insan duygularını ve arzularını fark etmek zorundadır. İyi insan duyguların gücünü ve rasyonel aklın duyguların gücünün üstesinden gelme becerisini kavramalıdır (Celano, 2016). Bu, duyguların bilgeliğin temel bileşeni olarak öne çıkan nitelikte "bilgi kaynakları" olduğunu işaret etmektedir. Duyguların, fark edilmesi ve üstesinden gelinmesi gerektiği düşünüldüğünde, hem pratik bilgelik (phronesis), hem aşkın bilgelikle (sophia) ilişkili olduğu belirtilebilir. Bu kapsamda Sokrates'in "kendini bil" ifadesi hatırlanabilir (Trowbridge ve Ferrari, 2011, s.91). Ayrica Afrika'da Kenyalı bilgelerin sevgi ve diğerkâmlık gereksinimini vurguladığı, insan duygularının genişliğine kavranmasını önemsediği belirtilmektedir (Presbey, 1999, s.89).

Duygularla Yunus Emre'nin ilişkisine yakından bakıldığında, Yunus Emre'nin duygular ile insani arzuları (nefs) ayırdettiği görülür. Yunus Emre "aşk" duygusunu ön plana almaktadır. "Ne akılem, ne divane, gel gör beni '1şk n'eyledi" (Yunus Emre, 2014) deyişii, aşk duygusunu yüceltmektedir. Bu açıdan, Yunus Emre'nin insanı insan yapan bileşenlerin varlığını kabul ettiği, ancak duygular arasında bir değer sıralaması yaptığı, aşk ve sevgiyi ön planda gördüğü söylenebilir.

Genel olarak bilgi kavramıyla ilişkisine yakından bakıldığında ise Yunus Emre'nin, kişi için anlam taşımayan ve/veya kişiye anlam kazandırmayan bilgiye mesafeli olduğu söylenebilir. "Sen kendüni bilmezsin, ya niçe okumakdur" (Yunus Emre, 2014) ifadesi, kişinin sahip olabileceği en anlamlı bilginin kendisine dair bilgi olduğu; buna katkı sunmayan okumanın işlevinin sorgulanması gerektiği görüşünü yansıtmaktadır. Ayrıca "ilmile hikmetile kimse irmez bu sırra, bu bir acayib sirdur, ilme kitaba sıgmaz" (Yunus Emre, 2014) dizeleri, önemli nitelikteki bilgiye isteyen herkesin ulaşamayacağı görüşüne sahip olduğunu göstermekte olabilir.

Yunus Emre'nin döneminden günümüze uzanan zamansal yolculukta batı dünyasında felsefe ve bilimsel gelişimdeki sıçrama dönemi dikkat çekmektedir. Bu kapsamda, 17. ve 18. yüzyılların bilimsel-felsefi dâhileri Galileo, Descartes, Newton vb. entelektüel olarak parlak bir görünüm sergileyip, etik boyuta aynı ölçüde vurgu yapmadıkları için bilge olmaktan çok filozof olarak nitelenmektedirler (McDermott, 2014, s.188). Bu kapsamda yapilan yorumlara göre, felsefi sorgulamayı yaşamın sorunlarından ayrı gören kişiler, teknik filozof olarak nitelenmiştir. Modernitenin bazı filozoflarının (Hobbes, Hume) hayatın keşfedilecek anlamı olmadığı fikrine sahip oldukları belirtilmektedir. Ancak bu konuda her düşünür aynı görüşte değildir. Örneğin, Sokrates, Plato, Aristoteles, Montaigne, Spinoza hayatın anlamı olmadığ katılmamaktadır (Presbey, 1999, s.101). Bu, bilgelik ve felsefe açısından bilginin nasıl görüldüğünün, perspektif sahibi bireye göre değiştiği anlamına gelmektedir.

Örneğin Aristoteles'e göre insanoğlu bilmeyi arzu eder. Aristoteles, bilge kişinin her şeyi genel olarak bildiğini ve aynı zamanda zor şeyleri bilme kapasitesi olduğunu, daha kapsayıcı bilgisi olduğunu ve son olarak nedenleri açıklama kabiliyeti olduğunu belirtir (Benardete, 1978, s.211). Bilgelik bilginin bir parçası değil, aksine bilgi bilgeliğin bir parçasıdır (Blanchard-Fields ve Norris, 1995). Dolayısiyla bilgelik bilgiye indirgenemez. Bilgi, anlayış/kavrayış için yeterli koşul olarak anlaşılmamalıdır. Anlayış olmadan bilgi mevcutsa yıkıcı potansiyel vardır çünkü amacı olmayan bilgi söz konusudur (Wirzba ve Benson, 2008). Descartes ise her bireyin hakikate erişebileceği bir akıl yürütme yönteminin imkânı üzerine odaklanmış ve bu konu üzerinde çalışmıştır. Ona göre, "düşünce"nin ne olduğunu bilmek için düşünmek yeterlidir (Descartes, 2015; s.58). Bu bakış açısı, bilgeliğin meydana gelmesinde rolü olan bilgiye, iyi işleyen bir zihne sahip herkesin ulaşabileceğini ifade etmektedir. Descartes, zihni özellikle vurgulamaktadır çünkü duyulardan alınan bilgilerin güvenilir olma düzeyinin tartış1lır olduğunu düşünmektedir. 
Bilgelik aynı zamanda psikolojik iç görüyü gerektirir. Bu da bilinçdışının derin bilgisine sahip olmak anlamına gelmektedir. Jung bireyleşmeyi benliğin bilinçli ve bilinçdışı boyutlarının bütünleşmesi olarak tanımlamaktadır (McDermott, 2014, s.189). Bu üç düşünürün görüşleri birlikte ele alındığında, bilgeliğin, kişinin dışından gelen bilgi ve içeride benliğine dair bilginin bir araya getirilmesi ile meydana geldiği söylenebilir.

\section{Yaşamın Anlamı Üzerine Yunus Emre’nin Görüşlerinin Diğer Bazı Filozoflar ile Birlikte Değerlendirilmesi}

Tüm düşünürler, kendilerini konumlandırdıkları yerden yaşamı yorumlamıştır. Antik Yunan'a baktığımızda, yaşamın tüm alanları hakkında düşünen bireyler karşımıza çıkmaktadır. Örneğin Aristoteles, dünyaya bir filozof olarak bakmıştır ve ona göre filozofun görevi, soyut bilim ortaya koymak değil, kendisini ve diğerlerini iyi yapmaktır (Celano, 2016, s.12). Sokrates'e göre, erdemli bir hayat yaşamak, bir filozofun görevidir (Presbey, 1999, s.90). Platon'un mağara anlatısı da toplum içinde aydınlatıcı görevi üstlenen bir kişiyi simgeleştirmektedir.

Mağara öyküsü, toplumun geleneksel bilgeliği ile tatmin olmayan kişinin spiritüel/ruhsal/manevi yolculuğudur. Platon'un anlattığı bu yolculuğun iki kısmı vardır: İlki, kişisel özgürleşme, ikincisi mağaraya dönüp diğerlerine yardım etme. İkinci kısım eksikse, elde edilen fayda benlikle sınırlı kalır. Spiritüel aydınlanmanın en yüksek amacı benlikten uzaklaşmadır. Benliği kutlamak değil, benliğin üstesinden gelmektir. Spiritüellik bilgeliğin kalbidir. Çünkü entelektüel kavrayışın duygusal çekirdeğidir (White, 2013, s.8). Özetle, filozoflar, bir filozofun görevi ne olmalı sorusunu cevaplamaya çalışmıştır. Bu görev, bazı düşünürler için kendi yaşamını erdemli yaşamakla sınırlı iken, diğer bazı düşünürler, filozofun çevresi/toplumu açısından da aydınlatıcı olması gerektiğini ifade etmiştir.

Yunus Emre, felsefi sorgulamada bulunan diğer kişiler gibi yaşamın anlamı üzerine düşünmüştür. Yunus Emre'nin düşüncelerini şiirleri vasitasıyla öğrenebiliyoruz. Şiirleri incelendiğinde, hem kendi nitelikleri, duyguları ile ilgili akıl yürüttügünü, hem de şiiri okuyan belirsiz okuyucuya da sorular yönelttiği görülmektedir. Bu sorularla bu dünyadaki insan davranışlarını ve bu dünya yaşamının nihai amacı olarak ilahi aşkı dile getirir. Yunus Emre'ye göre yaşamın anlamının ilahi aşk olduğu söylenebilir. Şiirlerinde "doğru olan budur" mesajı veren kesin ifadeler bulunmamakta, daha çok okuyucuya soru sorarak görüşünü belirtmektedir. $\mathrm{Bu}$ tutumun alt yapısını, "önemli/değerli bilginin" insana sezgisel olarak ulaşacağı inancı oluşturmaktadır. Bu Platon'un mağara anlatısında belirtilen spiritüel/manevi yolculuğu hatırlatmaktadir.

Sezgiyle ulaşılan bilgi açısından bakıldığında, insanın bir filozofun analitik becerisine sahip olmaksızın bilge olabileceği ya da bilgeliğe sahip olmadan isabetli tespitler yapabileceği belirtilmektedir (Oruka, 1991). Bu, bilgelik ile felsefi düşünme becerisinin doğrusal ilişkiye sahip olması gerekmediğini göstermektedir. Felsefe, belirli konularda dikkatli akıl yürütmeden meydana gelmektedir. Filozoflar, kendi fikirlerini destekleyecek iddialarla özellikle ilgilidir (Soccio, 2015, s.12). Sezgi ise duyularla aklın bir araya gelip meydana getirdiği bir yeti olarak kavramsallaştırılmaktadır (Arslan, 2017, s.349).

Yunus Emre'nin yazdığı şiirler iddialarını kanıtlama gayreti sergilememektedir. Şiir, Yunus Emre'nin döneminden bugüne, kişilerin yaşantıları, belirli duyguları ve derinlemesine düşünmelerinin bir sonucu olarak ortaya çıkan sanatsal bir eserdir. Şiir bilginin ne olduğuna dair diğer sanatlardan daha az şey ortaya koymaktadır. Bununla birlikte şiir okuyucuya diğer sanatlardan daha felsefi sorular yöneltmektedir (Benardete, 1978, s.214). Şairler filozof olarak nitelenmese de felsefi bir yansıtıcı düşünme gerçekleştirmektedir. Burada önem verilmesi gereken, felsefi akıl yürütmenin niteliğidir (Soccio, 2015, s.14). Dolayısıyla Yunus Emre'nin, kendisi ve okuyanlara sormak istediği soruları, bu nedenle şiirle ifade ettiği ileri sürülebilir. 


\section{Tartışma}

Bu makalede, Yunus Emre'nin yaşam öyküsü ve bakış açısı, bilgelik, felsefe ve bilgeliğin felsefesi kavramları ile ele alınmıştır. Yunus Emre, İslam kültürünün esaslarına vakıf, Kur'anı'ını okumuş bir Müslümandır, ama aynı zamanda içinde yaşadığı dünyayı, kendisinden beslendiği kültürü aşmak amacında olan bir kişidir (Arslan, 2017, s.362). Bu perspektifle bakıldığında, Yunus Emre'nin, içinde yaşadığı kültürün özelliklerini yaşama ile felsefi düşünmeyi bir arada gerçekleştirebildiği ileri sürülebilir.

Yunus Emre'nin yaşam öyküsünü neden anlamak isteyebiliriz? Bu, 2021 y1lında neden anlamlı bir amaç olabilir? Bu soruların yanıtı, günümüz bireyi ve toplumunun yaşadığı sorunları düşünerek verilebilir. Günümüz insanına eleştirel yaklaşan iki düşünür, Erich Fromm ve Jean Baudrillard'ın görüşlerine yakından bakarsak, Fromm'a (2015) göre bireyin ve toplumun önde gelen problemlerinden biri, mutlu olmaya bağlamdan kopuk olarak değer atfetmek ve bilgiyi derinlikten uzak bir hırsla talep etmektir. Ona göre bilmek, gerçeği araştırarak ona hep biraz daha fazla yaklaşma çabasıdır (Fromm, 2015, s.65). Baudrillard (2015) ise görünürde bir bolluk olsa bile, bunun mutluluk göstergelerinin biriktirilmesi ile meydana geldiğini ve bunun sağliklı olmadığına işaret etmektedir. İnsanın anlam arayışı, dünyayı anlamlandırma çabası halen sürmektedir. Yalın sorular soran Yunus Emre, hem rasyonel aklı hem de duyguları ele almıştır. İnsan1, tüm özellikleri ile kabul eden bir perspektife sahiptir. İnsanı anlamaya çalışmaktadır. Bu nedenle, felsefeden uzak olmadığı söylenebilir.

Bilgelik, bilgi gibi sadece kişisel anlamla sınırlı değildir, kurumsal ve sosyal anlamda da ele alınır. Bilgelik felsefesini, yaşamanın daha bilgece yollarını, daha bilge kurumları, gelecekleri ve sosyal ilişkileri, daha bilgece bir dünyayı geliştirmede, destek olan akılcı sorgulamanın en temel görevi olarak yorumlayabiliriz. Dünya üzerinde yaşamı anlamlı ve değerli hale getirebilmenin yollarını bulmak, bilgeliğin felsefesinin önemli amaçlarındandır (Maxwell, 2007). Düşünürler, bilgeliğin yok oluşu ile insanın kendisini dünyaya ait hissetmemesi olgusunun ilişkili olduğunu ileri sürmektedirler. Bilgelik, temel duygularla bilgilendirilen sabırlı, eğitici deneyimi yansıtmaktadır (Wirzba ve Benson, 2008). Bugün bu deneyimi ne ölçüde değerli bulduğumuz, kendimize sormamız gereken bir soru gibi görünmektedir. Çünkü çağımızda bireyin, kendisi bilincinde olmasa dahi, yaşamın anlamına dair sorgulamayı yaptığı düşünülmektedir.

Yunus Emre, insana dair temel soruları sormuştur. Bilgeliğin felsefesi, insanın değerli olana karar verirken geçtiği akılcı sorgulama sürecini kapsamaktadır. Yunus Emre, kendisi ve genel olarak insanlar için asıl değerli olanı anlamak için, bilgeliğin felsefesi kapsamında düşünmüştür. Eserlerinin de bu süreçlerden kaynaklandığı söylenebilir. Felsefi açıdan Yunus Emre'yi değerlendiren Arslan (2017), şiirden beklenmesi gereken şeyin, insanlık durumu hakkında sezgi veya duyarlılık vermesi olduğunu, Yunus Emre'nin, insanın trajik durumunu etkili bir şekilde ifade eden bir sanatçı olduğunu belirtmektedir (Arslan, 2017, s.354).

Şiir bir sanattır ve sanatın insana çeşitli şekillerde yardım edici işlevleri bulunduğu belirtilmektedir. Örneğin sanat, doğamızı dengelememize yardımcı olur, kendimizi tanımamızda bize yol gösterir, dağarcı̆̆ımızı genişletmeye teşvik eder ve hassasiyetlerimizi canlandırır (de Botton ve Armstrong, 2013; s. 65). Şiirin ise diğer sanatlarla karşılaştırıldığında daha felsefi sorular yöneltmekte olduğu ifade edilmektedir (Benardete, 1978, s.214). Dolayısıyla, Yunus Emre'nin bilgeliğin felsefesi çerçevesinde düşündüğü ve eser verdiği, bu eserleri felsefi soru sormak için en uygun sanat olan şiir ile ortaya koyduğu düşünülmektedir.

\section{Sonuç ve Öneriler}

Binlerce y1ldır milyonlarca insan yaşamın temel sorularını anlamaya çalışmış, bazıları başkalarına öğretmiş ya da yazmıştır. Bu iç görüler dünyadaki edebiyatlara, psikolojilere ve felsefelere katkı sunmuştur (Walsh, 2014). Bu bireyler, insana kendi bakış açılarına göre odaklanmıştır. Örneğin Descartes, kendisinden asla şüphe duyulamayacak bilgiye ulaşmaya 
önem atfetmiştir. $\mathrm{Bu}$, bilimsel bilginin gelişmesi açısından önem taşıyan bir noktadır ve Descartes bu konudaki çalışmalarıyla tarihsel anlamda kritik bir rol oynamıştır. Ayrıca içinde yaşadığı çağda, çevresindeki bireylerin genel inanışları açısından uyumsuz bulunabilecek görüşler de oluşturmuş ve yaşamı boyunca fikirlerini açıklama kararı verirken ihtiyatlı davranmıştır. Yunus Emre de belirli bir toplumsal gerçeklik içinde kendi zihinsel ve ruhsal gelişimini sağlamaya çalışmıştır. Bu toplumsal gerçekliği anlamaya çalışırken, eserlerinde yönelttiği sorular ile zaman zaman okuyucusunu halihazırda düşündüğünden farklı düşünmeye davet etmiştir. $\mathrm{Bu}$ açıdan bakıldığında, önemli düşünürlerin Platon'un mağara öyküsünü hatırlatan bir çizgileri olduğu akla gelmektedir. Kişisel ilerleyiş/özgürleşme aşamasının ardından topluluklarına destek olma amacına yönelik çalışmaktadırlar.

Yunus Emre'nin, çeşitli disiplinlerin kavşağında yer alan bilgelik kavramı bakımından değerlendirilmesinin önem taşıdığı düşünülmektedir. Ayrıca, Yunus Emre'nin felsefi bakımdan ele alındığı çalışmaların (örn. Arslan, 2017) devam etmesi gerektiği ifade edilebilir. Son olarak, bilgeliğin felsefesi konusunda Türkçe yayınların olması ve bu yayınların artmasının, Yunus Emre gibi Türk kültürel hazinelerinin daha iyi anlaşılabilirliğine yardım edebileceği düşünülmektedir. Yunus Emre mütevazı bir tutuma sahip, bununla beraber özne olma niteliğine sahip çıkan bir insandır. Bu özelliklerin bileşkesi, felsefe için uygun bir zihinsel yapıyı meydana getirmektedir. Yunus Emre'yi bu perspektifle anlamaya çalışmanın, insanlığın gelişimini destekleyeceği öngörülmektedir.

\section{Kaynakça}

Aldwin, C.M. (2009). Gender and wisdom: A brief overview, Research in Human Development, $6,1-8$.

Arslan, A. (1999). Felsefeye giriş. Vadi Yayınları.

Arslan, A. (2017). Tasavvuf ve Yunus Emre. "İslam felsefesi üzerine" içinde, (ss.339-363). İstanbul Bilgi Üniversitesi Yay.

Baudrillard, J. (2015). Tüketim toplumu. İstanbul: Ayrınt1 Yayınları.

Benardete, S. (1978). On wisdom and philosophy: The first two chapters of Aristotle's "Metaphysics", The Review of Metaphysics, 32(2), 205-215.

Blanchard-Fields, F. ve Norris, L. (1995). The development of wisdom. "Aging, spirituality and religion" içinde, Ed. M.A. Kimble, S.H. McFadden, J.W. Ellor ve J.J. Seeber, (ss. 102-118). MN: Forstress Press.

Celano, A. (2016). Aristotle's Ethics and medieval philosophy. Cambridge University Press.

de Botton, A. ve Armstrong, J. (2013). Terapi olarak sanat. The School of Life/Everest Yayınları.

Descartes, R. (2015). Tabiat ışı̆̆ı ile hakikati arama. İstanbul: Say Yayınları.

Fromm, E. (2015). Sahip olmak ya da olmak. İstanbul: Say Yayınları.

Husserl, E. (2017). Fenomenoloji üzerine beş ders. 4. Bs. (Giriş ve çeviri: H. Tepe) Ankara: BilgeSu Yayınc1lik.

Jaspers, K. (2003). Way to wisdom: An introduction to philosophy. Yale University Press.

Maxwell, N. (2007). From knowledge to wisdom. Pentire Press.

McDermott, R. (2014). Wisdom in western philosophy. "The World's Great Wisdom" içinde, Ed. R. Walsh, (ss.185-212). Suny Press.

Oruka, H.O. (1991) (Ed.) Sage philosophy: Indigenous thinkers and modern debate on African philosophy. Nairobi: African Centre for Technology Studies. 
Presbey, G.M. (1999). The wisdom of African sages, New Political Science, 21(1), 89-102.

Seligman, M.E.P. ve Csikszentmihalyi, M. (2000). Positive psychology: An introduction, American Psychologist, 55(1), 5-14.

Soccio, D.J. (2015). Archetypes of wisdom. Cengage Learning.

Tatc1, M. (2020). Yunus Emre Divanı. İstanbul: H Yayınları.

Trowbridge, R.H. ve Ferrari, M. (2011). Sophia and phronesis in psychology, philosophy and traditional wisdom, Research in Human Development, 8(2), 89-94.

Walsh, R. (2014). The world's great wisdom: An integral overview. "The World's Great Wisdom" içinde, Ed. R. Walsh, ss. 213-258. Suny Press.

White, R. (2013). The heart of wisdom. Rowman\&Littlefield Publishers, Inc.

Wirzba, N. ve Benson, B.E. (2008)(Ed.) Transforming philosophy and religion. Indiana University Press.

Yunus Emre (2014). Divan-ı Yunus Emre. TBMM Kütüphanesi Açık Erişim Koleksiyonu. http://hdl.handle.net/11543/991

ETIKK ve BİLIMSEL İLKELER SORUMLULUK BEYANI

$\mathrm{Bu}$ çalışmanın tüm hazırlanma süreçlerinde etik kurallara ve bilimsel atıf gösterme ilkelerine riayet edildiğini yazar(lar) beyan eder. Aksi bir durumun tespiti halinde Afyon Kocatepe Üniversitesi Sosyal Bilimler Dergisi'nin hiçbir sorumluluğu olmayıp, tüm sorumluluk makale yazarlarına aittir.

\section{ARAȘTIRMACILARIN MAKALEYE KATKI ORANI BEYANI}

1. yazar katkı oranı : \%100 